\title{
Combination of irinotecan and platinum for platinum-resistant or refractory recurrent ovarian cancers: A preliminary case series
}

\author{
TAKASHI SHIBUTANI ${ }^{1}$, MASASHI TAKANO ${ }^{2}$, MORIKAZU MIYAMOTO $^{1}$, TOMOYUKI YOSHIKAWA ${ }^{2}$, \\ TADASHI AOYAMA ${ }^{1}$, HIROAKI SOYAMA ${ }^{1}$, JUNKO HIRATA ${ }^{1}$, AYAKO SUZUKI ${ }^{1}$, \\ HIDENORI SASA $^{1}$ and KENICHI FURUYA ${ }^{1}$ \\ Departments of ${ }^{1}$ Obstetrics and Gynecology and ${ }^{2}$ Clinical Oncology, National Defense \\ Medical College Hospital, Tokorozawa, Saitama 359-8513, Japan
}

Received August 11, 2016; Accepted March 16, 2017

DOI: $10.3892 / \operatorname{mco} .2017 .1258$

\begin{abstract}
Non-platinum single agents are usually used for patients with platinum-resistant recurrent ovarian cancers (ROC). However, the efficacy of these drugs is limited. The aim of the present study was to evaluate the efficacy and adverse events (AE) of combination therapy with irinotecan and platinum (CPT-Pt) for ROC. A total of 28 platinum-resistant or refractory patients with ROC treated with CPT-Pt at the National Defense Medical College Hospital institution between 2002 and 2012 were identified. All patients received taxane and carboplatin (TC) as a first-line treatment and relapsed within 6 months after completion of TC, or progressed during TC therapy. The median age was 59 years (range, 16-78), and median number of CPT-Pt therapy cycles was 5.5 (range, 2-16). The overall response rate was $14 \%$, with a complete response (CR) in 2 patients and partial response (PR) in 2 patients. Stable disease (SD) for $>3$ months was observed in 15 patients (54\%), resulting in a clinical benefit rate $(\mathrm{CBR}=\mathrm{CR}+\mathrm{PR}+\mathrm{SD})$ of $68 \%$. The median progression-free survival and overall survival were 8 and 15 months, respectively. Fifteen cases (68\%) developed grade 3/4 hematological AE and 3 cases (11\%) developed non-hematological grade 3/4 AE, which were resolved by conservative management or dose reduction. Platinum re-treatment with irinotecan for platinum refractory or resistant ROC may be a candidate in such clinical settings.
\end{abstract}

\section{Introduction}

Platinum-based agents have been key drugs for epithelial ovarian cancer during the past three decades (1). The standard treatment for ovarian cancer is debulking surgery followed by

Correspondence to: Dr Masashi Takano, Department of Clinical Oncology, National Defense Medical College Hospital, 3-2 Namiki, Tokorozawa, Saitama 359-8513, Japan

E-mail: mastkn@ndmc.ac.jp

Key words: irinotecan, platinum, recurrent ovarian cancer, platinum-resistant a combination of taxanes and carboplatin (TC), but more than half of cases with advanced disease relapse (2). Relapse within 6 months after the last platinum-based therapy is defined as platinum-resistant recurrence (Pt-R) (3), and non-platinum single agents such as pegylated liposomal doxorubicin, paclitaxel, topotecan and gemcitabine are commonly used for patients with Pt-R recurrent ovarian cancer (ROC) (4). Among these drugs, there appear to be no differences in response rate (10-15\%), progression-free survival (PFS) (3-4 months) and overall survival (OS) (approximately 12 months) (5-10). Due to the poor prognosis of patients with Pt-R ROC by these treatments, novel agents including molecular-targeting drugs have been investigated to overcome platinum-resistance.

The efficacy of administration of platinum re-treatment for Pt-R ROC has not yet been established. Weekly paclitaxel with carboplatin for Pt-R ROC had no advantage in terms of PFS compared with weekly paclitaxel alone (11). By contrast, dose-dense weekly administration of platinum agents has been reported to extend PFS for Pt-R ROC in recent years $(12,13)$. Additionally, patients with Pt-R ROC may benefit again from platinum-based chemotherapy following the longer interval until platinum re-treatment with non-platinum single agents (14). Therefore, by modified method or timing of platinum administration, platinum re-treatment is potentially effective for Pt-R ROC.

Irinotecan (CPT), a topoisomerase-1 inhibitor, has modest activity for patients with Pt-R ROC $(15,16)$, and has synergic effects in combination with cisplatin (CPT-P) in vitro (17). Furthermore, the combination of CPT and CPT-P was reported to be effective for patients with Pt-R ROC $(18,19)$. The present study was performed to retrospectively evaluate the efficacy and adverse events (AE) in 28 patients treated with irinotecan and platinum (CPT-Pt) for Pt-R ROC.

\section{Patients and methods}

Patients. Platinum-resistance recurrence (Pt-R) was defined as a relapse within 6 months from the last platinum-based chemotherapy. After approval by the Institutional Review Board of the institution, a total of 28 patients with Pt-R ROC treated with CPT-Pt at the National Defense Medical College Hospital (Tokorowaza, Japan) between January, 2002 and December, 
Table I. Characteristics of the patients.

\begin{tabular}{|c|c|}
\hline Characteristic & Number of patients (\%) \\
\hline Total & 28 cases \\
\hline Age, years & 57.5 \\
\hline Median (range) & $(16-78)$ \\
\hline \multicolumn{2}{|l|}{ PS } \\
\hline 0 & $28(100)$ \\
\hline \multicolumn{2}{|l|}{ FIGO stage } \\
\hline $\mathrm{I} / \mathrm{II}$ & $3(11)$ \\
\hline II/IV & $25(89)$ \\
\hline \multicolumn{2}{|l|}{ Histology } \\
\hline Serous AC & $17(60)$ \\
\hline Endometrioid AC & $1(4)$ \\
\hline Clear cell AC & $4(14)$ \\
\hline Mucinous AC & $1(4)$ \\
\hline $\mathrm{AC}, \mathrm{NOS}$ & $5(18)$ \\
\hline \multicolumn{2}{|c|}{ Residual disease at primary surgery, $\mathrm{cm}$} \\
\hline$<1$ & $12(43)$ \\
\hline$\geq 1$ & $16(57)$ \\
\hline \multicolumn{2}{|l|}{ Status of platinum resistance } \\
\hline Platinum-refractory & $12(43)$ \\
\hline Primary platinum resistance & $10(36)$ \\
\hline Secondary platinum resistance & $6(21)$ \\
\hline \multicolumn{2}{|c|}{ Number of prior chemotherapy regimens } \\
\hline 1 & $22(78)$ \\
\hline 2 & $3(11)$ \\
\hline 3 & $3(11)$ \\
\hline \multicolumn{2}{|l|}{ CPT-Pt regimens } \\
\hline 5-day CРТ-P & $13(46)$ \\
\hline wCPT-P & $9(32)$ \\
\hline wCPT-N & $5(18)$ \\
\hline wCPT-C & $1(4)$ \\
\hline \multicolumn{2}{|l|}{ UGT1A1 } \\
\hline Wild-type & $9(32)$ \\
\hline Hetero-type $(* 6)$ & $3(11)$ \\
\hline Hetero-type $(* 28)$ & $2(7)$ \\
\hline Not available & $14(50)$ \\
\hline
\end{tabular}

PS, performance status; FIGO, International Federation of Gynecology and Obstetrics; AC, adenocarcinoma; NOS, not otherwise specified; CPT-Pt, irinotecan and platinum; CPT-P, irinotecan and cisplatin; wCPT-P, weekly irinotecan and cisplatin; wCPT-N, weekly irinotecan and nedaplatin; wCPT-C, weekly irinotecan and carboplatin; UGT1A1, uridine diphosphate glucuronosyltransferase 1A1.

2012 were identified from a retrospective review of medical charts. All patients received combination therapy with TC as the first-line chemotherapy, and received CPT-Pt for the treatment of recurrent tumors with Pt-R. Platinum-resistance was sub-classified as follows (14,20): i) Platinum-refractory, patients who relapsed during TC therapy; ii) primary platinum-resistance, patients who relapsed within 6 months after the primary TC therapy; and iii) secondary platinum-resistance, patients
Table II. Adverse events of CPT-Pt regimens according to CTCAE version 4.0 .

CTCAE grade of adverse event (n)

\begin{tabular}{lrrrr}
\cline { 2 - 5 } Adverse event & 2 & 3 & 4 & $3 / 4(\%)$ \\
\hline $\begin{array}{l}\text { Hematologic } \\
\text { toxicities }\end{array}$ & & & & \\
$\quad$ Anemia & 16 & 6 & 0 & $6(21)$ \\
$\quad$ Neutropenia & 5 & 11 & 8 & $19(68)$ \\
Thrombocytopenia & 3 & 3 & 3 & $6(21)$ \\
Febrile neutropenia & 0 & 3 & 0 & $3(11)$ \\
Non-hematologic & & & & \\
toxicities & & & & \\
$\quad$ Diarrhea & 7 & 3 & 0 & $3(11)$ \\
Nausea/vomiting & 2 & 1 & 0 & $1(4)$ \\
Anorexia & 2 & 1 & 0 & $1(4)$ \\
Allergic reaction & 2 & 1 & 0 & $1(4)$
\end{tabular}

CPT-Pt, irinotecan and platinum; CTCAE, Common Terminology Criteria for Adverse Events.

who relapsed within 6 months after the second-line therapy with platinum-based regimen for the first relapse following primary TC therapy.

Treatment. Four CPT-Pt regimens were used for the patients with Pt-R ROC: i) Five-day CPT-P, irinotecan $22.5 \mathrm{mg} / \mathrm{m}^{2}$ and cisplatin $10 \mathrm{mg} / \mathrm{m}^{2}$ on days $1-5$, once every 4 weeks; ii) weekly (w)CPT-P, irinotecan $40-60 \mathrm{mg} / \mathrm{m}^{2}$ on days 1,8 , and 15 and cisplatin $50-60 \mathrm{mg} / \mathrm{m}^{2}$ on day 1 , once every 4 weeks; iii) weekly CPT-nedaplatin (wCPT-N), irinotecan $40-60 \mathrm{mg} / \mathrm{m}^{2}$ on days 1 , 8 and 15 and nedaplatin $60 \mathrm{mg} / \mathrm{m}^{2}$ on day 1 , once every 4 weeks; and iv) weekly CPT-carboplatin (wCPT-C), irinotecan $40-60 \mathrm{mg} / \mathrm{m}^{2}$ on days $1,8,15$ and carboplatin target area under the concentration vs. time curve $=5$ on day 1 , once every 4 weeks. Five-day CPT-P was used between 2002 and 2007. From 2007, other regimens aside from five-day CPT-P were selected by clinicians according to kidney function and history of allergic reactions. CPT-Pt regimens were administrated until progression of the disease or development of unacceptable AE. Approximately $80 \%$ of the initial dose of CPT-Pt was delivered in subsequent cycles when the patients developed severe AE (grade $\geq 3$ ) in prior cycles. Uridine diphosphate glucuronosyltransferase 1A1 (UGT1A1) genotyping was available in approximately half of the cases, and the incidences of severe AE grade $>2$ were analyzed according to UGT1A1 genotype.

Assessments. Performance status (PS) was evaluated according to the Eastern Cooperative Oncology Group criteria (21). Response to treatment was assessed by computed tomography (CT) imaging using Response Evaluation Criteria in Solid Tumors (RECIST) guidelines (version 1.1) (22), or cancer antigen (CA)-125 criteria defined by Rustin et al (23). CA-125 levels were checked before every cycle. CT was performed every 2-3 cycles, or when disease progression was clinically suspected. Clinical benefit rate (CBR) was defined 
Table III. Grade 3/4 adverse events of CPT-Pt regimens according to UGT1A1 genotype.

\begin{tabular}{|c|c|c|c|c|}
\hline Adverse event & $\begin{array}{l}\text { UGT1A1 wild-type, n (\%) } \\
\qquad(\mathrm{n}=9)\end{array}$ & $\begin{array}{l}\text { UGT1A1 hetero-type, n (\%) } \\
\qquad(\mathrm{n}=5)\end{array}$ & $\begin{array}{l}\text { UGT1A1 unknown, n (\%) } \\
\qquad(\mathrm{n}=14)\end{array}$ & P-value \\
\hline \multicolumn{5}{|l|}{ Hematologic toxicities } \\
\hline Anemia & $1(3)$ & $1(20)$ & $4(29)$ & 0.61 \\
\hline Neutropenia & $6(67)$ & $2(40)$ & $10(71)$ & 0.45 \\
\hline Thrombocytopenia & $1(3)$ & $1(20)$ & $4(29)$ & 0.61 \\
\hline Febrile neutropenia & $0(0)$ & $0(0)$ & $3(21)$ & 0.06 \\
\hline \multicolumn{5}{|c|}{ Non-hematologic toxicities } \\
\hline Diarrhea & $1(3)$ & $1(20)$ & $1(7)$ & 0.73 \\
\hline Nausea/vomiting & $1(3)$ & $0(0)$ & $0(0)$ & 0.33 \\
\hline Anorexia & $0(0)$ & $0(0)$ & $1(7)$ & 0.60 \\
\hline Allergic reaction & $0(0)$ & $1(20)$ & $0(0)$ & 0.09 \\
\hline
\end{tabular}

CPT-Pt, irinotecan and platinum; UGTA1, uridine diphosphate glucuronosyltransferase $1 \mathrm{~A} 1$.

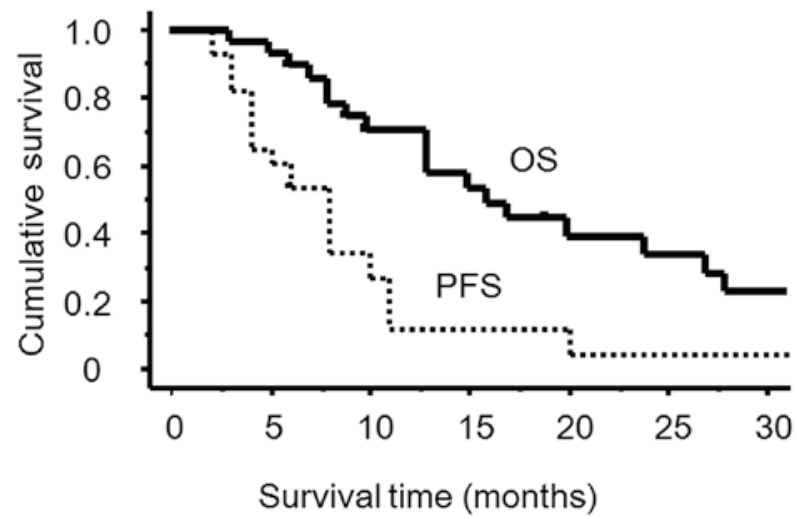

Figure 1. PFS and OS curves. The median PFS was 8 months (95\% CI, 4-10 months), and median OS was 15 months (95\% CI, 10-27 months). PFS, progression-free survival; OS, overall survival; CI, confidence intervals.

as the percentage of the patients who achieved complete response $(\mathrm{CR})$, partial response $(\mathrm{PR})$ and stable disease $(\mathrm{SD})$ to all enrolled patients (24). AE were assessed using Common Terminology Criteria for AE version 4.0 (25). PFS was defined as the period of time between the date of the first cycle of CPT-Pt and the date of progression or mortality. OS was defined as the period of time between the date of the first cycle of CPT-Pt and mortality.

Statistical analysis. The $\chi^{2}$ test was used to evaluate difference in patient's characteristics and the incidence of AE. Survival curves were generated using the Kaplan-Meier method, and a 95\% two-sided confidence interval (CI) was also estimated. Survival variation among the regimens was analyzed using log-rank test. The data was analyzed using StatView software version 5.0 (SAS Institute Inc., Cary, NC, USA). P<0.05 was considered to indicate a statistically significant difference.

\section{Results}

The patient characteristics are presented in Table I. The median age of the patients was 59 years (range, 16-78) and their PS was 0 . The median number of administrated cycles was 5.5 (range, 2-16). Thirteen patients received the 5-day CPT-P regimen, 9 patients received wCPT-P, 5 patients received wCPT-N and 1 patient received wCPT-C. Twelve patients (43\%) were platinum refractory, 10 patients $(36 \%)$ had primary resistance and 6 patients $(21 \%)$ had secondary resistance. In total, 25 patients were assessed for progression and response using CT imaging using RECIST guidelines (version 1.1), and other 3 patients were assessed using CA-125 criteria due to lack of measurable disease. The overall response rate was $14 \%$ : 2 patients with a CR and 2 patients with a PR. Additionally, 15 patients $(54 \%)$ achieved SD, resulting in a CBR of $68 \%$. There were no differences in CBR among platinum refractory disease, primary resistance cases and secondary resistance cases (67 vs. 70 vs. 67\%, respectively; $\mathrm{P}=0.93$ ). In addition, there was no difference in CBR between 5-day CPT-P and other regimens (69 vs. 67\%, $\mathrm{P}=0.99)$. The median PFS of 5-day CPT-P and other regimens were 8 and 6 months, respectively $(\mathrm{P}=0.27)$. A total of 21 patients $(75 \%)$ succumbed to disease, and the median follow-up time of these patients was 10 months (range, 6-94 months). The median PFS was 8 months (95\% CI $=4-10$ months), and the median OS was 15 months (95\% CI = 10-27 months) (Fig. 1).

There were no cases that developed treatment-related mortality, or that discontinued CPT-Pt therapy due to unmanageable AEs. AE are summarized in Table II. Neutropenia was the most common AE, and neutropenia of grade $>2$ was observed in $68 \%$ of the patients. Neutropenia was resolved by treatment delay, dose reduction of CPT-Pt, or administration of granulocyte-colony stimulating factor. Diarrhea and nausea/vomiting were also frequently observed. These non-hematological AEs were resolved by conservative management or dose reduction. Among all 28 patients, 15 patients required dose reduction of CPT-Pt in the subsequent cycle dose due to AE. Grade 1-3 diarrhea was observed more frequently in 5-day CPT-P compared with other regimens ( 85 vs. $20 \%$; $\mathrm{P}<0.01$ ). The incidence of severe AE of grade $>2$ according to UGT1A1 genotyping are presented in Table III. UGT1A1 genotypes were available in 14 cases: 9 cases with UGT1A1 wild-type and 5 cases with 
UGT1A1 hetero-type. There were no significant differences in the incidence of grade $3 / 4 \mathrm{AE}$ between these groups.

\section{Discussion}

Our preliminary data revealed that CPT-Pt for patients with Pt-R ROC achieved a CBR of $68 \%$, median PFS of 8 months and a median OS of 15 months. Although direct comparison was challenging due to patients' heterogeneity and the four treatment regimens, CPT-Pt had the potential to produce longer PFS compared with other non-platinum single agents such as gemcitabine and pegylated liposomal doxorubicin, which achieved a median PFS of 3-4 months (5-10). On the other hand, combination therapy with conventional chemotherapy with bevacizumab produced a PFS of 6.7 months (26). CPT-Pt regimens had a similar PFS compared with cisplatin/etoposide and paclitaxel/carboplatin (median PFS, $\sim 8$ months) $(12,13)$.

A previous study suggested that CPT combined with cisplatin had a CBR of $72 \%$ and the median PFS of 6 months in a case series of 25 patients including 21 patients with Pt-R ROC (7). By contrast, CPT combined with carboplatin had a CBR of 53\% and the median PFS of 3.7 months in 17 patients with Pt-R ROC (27). In the present study, 22 patients (79\%) received cisplatin in combination and only one patient received carboplatin in combination. At present, almost all patients with ovarian cancer receive the TC regimen as the first-line chemotherapy in general clinical practice. Although carboplatin was reported to show cross-resistance with cisplatin in vitro (26), the data from the present study suggested that patients with Pt-R ROC benefited from the combination of CPT with cisplatin, and not from CPT with carboplatin.

CPT-Pt for patients with Pt-R disease develop higher frequencies of grade $3 / 4$ hematological $\mathrm{AE}$, compared with single non-platinum single agents (5). In cancer patients treated with CPT, genotyping of UGT1A1 may be a useful predictive marker for severe AEs such as neutropenia $(28,29)$. UGT1A1 genotyping may allow the avoidance of severe AEs occurring as a result of the use of CPT-Pt for the treatment of Pt-R ROC, although there were no significant differences in the incidence of severe AE according to UGT1A1 genotype in the present case series. For the schedule of administration, grade 1-3 diarrhea was observed more frequently in the 5-day CPT-P group compared with other regimens in the present study. A weekly schedule of irinotecan, such as wCPT-P and wCPT-N regimens, may be safer for patients with Pt-R ROC.

Bevacizumab has been widely used for the treatment of ovarian cancer. However, it is inevitable that severe AEs, such as gastrointestinal perforation, may be observed in patients with ROC, particularly in the patients that had peritoneal dissemination $(24,30)$. CPT-Pt regimens might be an alternative treatment for patients with Pt-R ROC who may suffer from bevacizumab-associated AEs.

In conclusion, CPT-Pt achieved a longer PFS in patients with Pt-R ROC, although a slight elevation of AE frequency was observed compared with reported incidence by non-platinum single agents. Weekly schedules of irinotecan, such as wCPT-P and wCPT-N, may be safer regimens compared with 5-day CPT-P regimens. CPT-Pt may be a candidate regimen for the treatment of Pt-R ROC; however, further investigation is needed.

\section{References}

1. Muggia F: Platinum compounds 30 years after the introduction of cisplatin: implications for the treatment of ovarian cancer. Gynecol Oncol 112: 275-281, 2009.

2. Armstrong DK: Relapsed ovarian cancer: challenges and management strategies for a chronic disease. Oncologist 7 (Suppl 5): 20-28, 2002.

3. Markman M, Rothman R, Hakes T, Reichman B, Hoskins W, Rubin S, Jones W, Almadrones L and Lewis JL Jr: Second-line platinum therapy in patients with ovarian cancer previously treated with cisplatin. J Clin Oncol 9: 389-393, 1991.

4. Luvero D, Milani A and Ledermann JA: Treatment options in recurrent ovarian cancer: latest evidence and clinical potential. Ther Adv Med Oncol 6: 229-239, 2014.

5. Mutch DG, Orlando M, Goss T, Teneriello MG, Gordon AN, McMeekin SD, Wang Y, Scribner DR Jr, Marciniack M, Naumann RW and Secord AA: Randomized phase III trial of gemcitabine compared with pegylated liposomal doxorubicin in patients with platinum-resistant ovarian cancer. J Clin Oncol 25: 2811-2818, 2007.

6. Monk BJ, Herzog TJ, Kaye SB, Krasner CN, Vermorken JB, Muggia FM, Pujade-Lauraine E, Lisyanskaya AS, Makhson AN, Rolski J, et al: Trabectedin plus pegylated liposomal Doxorubicin in recurrent ovarian cancer. J Clin Oncol 28: 3107-3114, 2010.

7. Meier W, du Bois A, Reuss A, Kuhn W, Olbricht S, Gropp M, Richter B, Lück HJ, Kimmig R and Pfisterer J: Topotecan versus treosulfan, an alkylating agent, in patients with epithelial ovarian cancer and relapse within 12 months following 1st-line platinum/paclitaxel chemotherapy. A prospectively randomized phase III trial by the Arbeitsgemeinschaft Gynaekologische Onkologie Ovarian Cancer Study Group (AGO-OVAR). Gynecol Oncol 114: 199-205, 2009.

8. Buda A, Floriani I, Rossi R, Colombo N, Torri V, Conte PF, Fossati R, Ravaioli A and Mangioni C: Randomised controlled trial comparing single agent paclitaxel vs epidoxorubicin plus paclitaxel in patients with advanced ovarian cancer in early progression after platinum-based chemotherapy: an Italian Collaborative Study from the Mario Negri Institute, Milan, G.O.N.O. (Gruppo Oncologico Nord Ovest) group and I.O.R. (Istituto Oncologico Romagnolo) group. Br J Cancer 90: 2112-2117, 2004.

9. Gordon AN, Fleagle JT, Guthrie D, Parkin DE, Gore ME and Lacave AJ: Recurrent epithelial ovarian carcinoma: a randomized phase III study of pegylated liposomal doxorubicin versus topotecan. J Clin Oncol 19: 3312-3322, 2001.

10. ten Bokkel Huinink W, Gore M, Carmichael J, Gordon A, Malfetano J, Hudson I, Broom C, Scarabelli C, Davidson N, Spanczynski M, et al: Topotecan versus paclitaxel for the treatment of recurrent epithelial ovarian cancer. J Clin Oncol 15: 2183-2193, 1997.

11. Lortholary A, Largillier R, Weber B, Gladieff L, Alexandre J, Durando X, Slama B, Dauba J, Paraiso D and Pujade-Lauraine E; GINECO group France: Weekly paclitaxel as a single agent or in combination with carboplatin or weekly topotecan in patients with resistant ovarian cancer: the CARTAXHY randomized phase II trial from Groupe d'Investigateurs Nationaux pour l'Etude des Cancers Ovariens (GINECO). Ann Oncol 23: 346-352, 2012.

12. van der Burg ME, de Wit R, van Putten WL, Logmans A, Kruit WH, Stoter G and Verweij J: Weekly cisplatin and daily oral etoposide is highly effective in platinum pretreated ovarian cancer. Br J Cancer 86: 19-25, 2002.

13. Sharma R, Graham J, Mitchell H, Brooks A, Blagden S and Gabra H: Extended weekly dose-dense paclitaxel/carboplatin is feasible and active in heavily pre-treated platinum-resistant recurrent ovarian cancer. Br J Cancer 100: 707-712, 2009.

14. See HT, Freedman RS, Kudelka AP, Burke TW, Gershenson DM, Tangjitgamol S and Kavanagh JJ: Retrospective review: re-treatment of patients with ovarian cancer with carboplatin after platinum resistance. Int J Gynecol Cancer 15: 209-216, 2005.

15. Matsumoto K, Katsumata N, Yamanaka Y, Yonemori K, Kohno T, Shimizu C, Andoh M and Fujiwara Y: The safety and efficacy of the weekly dosing of irinotecan for platinum- and taxanes-resistant epithelial ovarian cancer. Gynecol Oncol 100: 412-416, 2006.

16. Bodurka DC, Levenback C, Wolf JK, Gano J, Wharton JT, Kavanagh JJ and Gershenson DM: Phase II trial of irinotecan in patients with metastatic epithelial ovarian cancer or peritoneal cancer. J Clin Oncol 21: 291-297, 2003. 
17. Fukuda M, Nishio K, Kanzawa F, Ogasawara H, Ishida T, Arioka H, Bojanowski K, Oka M and Saijo N: Synergism between cisplatin and topoisomerase I inhibitors, NB-506 and $\mathrm{SN}-38$, in human small cell lung cancer cells. Cancer Res 56: 789-793, 1996.

18. Sugiyama T, Yakushiji M, Nishida T, Ushijima K, Okura N, Kigawa J and Terakawa N: Irinotecan (CPT-11) combined with cisplatin in patients with refractory or recurrent ovarian cancer. Cancer Lett 128: 211-218, 1998.

19. Kigawa J, Takahashi M, Minagawa Y, Oishi T, Sugiyama T, Yakushiji $\mathrm{M}$ and Terakawa N: Topoisomerase-I activity and response to second-line chemotherapy consisting of camptothecin-11 and cisplatin in patients with ovarian cancer. Int $\mathbf{J}$ Cancer 84: 521-524, 1999.

20. Markman M and Bookman MA: Second-line treatment of ovarian cancer. Oncologist 5: 26-35, 2000.

21. Oken MM, Creech RH, Tormey DC, Horton J, Davis TE, McFadden ET and Carbone PP: Toxicity and response criteria of the Eastern Cooperative Oncology Group. Am J Clin Oncol 5: 649-655, 1982

22. Eisenhauer EA, Therasse P, Bogaerts J, Schwartz LH, Sargent D, Ford R, Dancey J, Arbuck S, Gwyther S, Mooney M, et al: New response evaluation criteria in solid tumours: revised RECIST guideline (version 1.1). Eur J Cancer 45: 228-247, 2009.

23. Rustin GJ, Nelstrop AE, McClean P, Brady MF, McGuire WP Hoskins WJ, Mitchell $\mathrm{H}$ and Lambert HE: Defining response of ovarian carcinoma to initial chemotherapy according to serum CA 125. J Clin Oncol 14: 1545-1551, 1996.

24. U.S. Department of Health and Human Services: Common Terminology Criteria for Adverse Events (CTCAE). https://evs. nci.nih.gov/ftpl/CTCAE/CTCAE_4.03_2010-06-14_QuickReference 8.5x11.pdf. Accessed March 17, $201 \overline{7}$.
25. Pujade-Lauraine E, Hilpert F, Weber B, Reuss A, Poveda A, Kristensen G, Sorio R, Vergote I, Witteveen P, Bamias A, et al: Bevacizumab combined with chemotherapy for platinum-resistant recurrent ovarian cancer: the AURELIA open-label randomized phase III trial. J Clin Oncol 32: 1302-1308, 2014.

26. Tsubamoto H, Kawaguchi R, Ito K, Shiozaki T, Takeuchi S, Itani Y, Arakawa A, Tabata T and Toyoda S: Phase II study of carboplatin and weekly irinotecan combination chemotherapy in recurrent ovarian cancer: a Kansai clinical oncology group study (KCOG0330). Anticancer Res 33: 1073-1079, 2013.

27. Misawa T, Kikkawa F, Maeda O, Obata NH, Higashide K, Suganuma N and Tomoda Y: Establishment and characterization of acquired resistance to platinum anticancer drugs in human ovarian carcinoma cells. Jpn J Cancer Res 86: 88-94, 1995.

28. Takano M, Kato M, Yoshikawa T, Sasaki N, Hirata J, Furuya K, Takahashi M, Yokota H, Kino N, Horie K, et al: Clinical significance of UDP-glucuronosyltransferase $1 \mathrm{~A} 1 * 6$ for toxicities of combination chemotherapy with irinotecan and cisplatin in gynecologic cancers: a prospective multi-institutional study. Oncology 76: 315-321, 2009.

29. Ichikawa W, Uehara K, Minamimura K, Tanaka C, Takii Y, Miyauchi H, Sadahiro S, Fujita K, Moriwaki T, Nakamura M, et al: An internally and externally validated nomogram for predicting the risk of irinotecan-induced severe neutropenia in advanced colorectal cancer patients. Br J Cancer 112: 1709-1716, 2015.

30. Cannistra SA, Matulonis UA, Penson RT, Hambleton J, Dupont J, Mackey H, Douglas J, Burger RA, Armstrong D, Wenham R and McGuire W: Phase II study of bevacizumab in patients with platinum-resistant ovarian cancer or peritoneal serous cancer. J Clin Oncol 25: 5180-5186, 2007. 